\title{
Randomized Controlled Trial of Cryoanalgesia (Ice Bag) to Reduce Pain Associated With Arterial Puncture
}

\author{
Jeffrey M Haynes RRT RPFT
}

\begin{abstract}
BACKGROUND: Arterial puncture can be a painful procedure for many patients. This study investigates whether precooling of a puncture site with ice can reduce the pain associated with arterial puncture. METHODS: This was a stratified randomized controlled trial of a convenience sample of out-patients with a physician order for an arterial blood gas (ABG) test. The intervention group had a plastic bag of ice applied to their wrists for 3 min before drawing an ABG sample from the radial artery. The control group had an ABG sample drawn from the radial artery without the application of ice. Pain from the arterial puncture was measured with a $100-\mathrm{mm}$ visual analog scale. RESULTS: Subjects pretreated with ice reported less pain from arterial puncture compared with subjects in the control group (mean visual analog scale $13.8 \pm 16.9$ vs $25 \pm 23 \mathrm{~mm}, P=.01$; median visual analog scale $7 \mathrm{~mm}$, interquartile range (IQR) $1.5-19$ vs $20 \mathrm{~mm}$, IQR $4.5-38.5 \mathrm{~mm}, P=.01$ ). Stratified analysis showed that visual analog scale pain scores were lower in the naive group when ice was applied (naive ice vs naive control: mean visual analog scale $11 \pm 14.3$ vs $26.5 \pm 25 \mathrm{~mm}$, $P=.02$; median visual analog scale $5 \mathrm{~mm}$, IQR 2-14.5 vs $20 \mathrm{~mm}$, IQR $6.5-36 \mathrm{~mm}, P=.02)$. Visual analog scale pain scores trended lower in the experienced group when ice was applied (experienced ice vs experienced control: mean visual analog scale $15.9 \pm 18.9$ vs $25.1 \pm 22 \mathrm{~mm}, P=.15$; median visual analog scale $8 \mathrm{~mm}$, IQR $0.5-26.5$ vs $23 \mathrm{~mm}$, IQR $3.5-40 \mathrm{~mm}, P=.08$ ). There was no difference in first-attempt success between groups (ice group: $85 \%$, control group: 82.5\%, $P>.99$ ). Only 3 subjects could not tolerate 3-min ice application. CONCLUSIONS: Ice application before arterial puncture is well tolerated and reduces procedure-related pain. (ClinicalTrials.gov NCT02065115). Key words: ice; cryotherapy; puncture; pain. [Respir Care 2015;60(1):1-5. (c) 2015 Daedalus Enterprises]
\end{abstract}

\section{Introduction}

Arterial blood gas $(\mathrm{ABG})$ testing requires puncture of an artery to obtain a blood specimen for analysis. Arterial punctures can be quite painful for many patients and are a major source of morbidity in critically ill patients. ${ }^{1}$ Randomized controlled trials (RCTs) of intradermal anesthetics have been shown to be effective in reducing ABG-

\footnotetext{
Mr Haynes is affiliated with the Pulmonary Function Laboratory, St Joseph Hospital, Nashua, New Hampshire.

Mr Haynes has disclosed no conflicts of interest.

Correspondence: Jeffrey M Haynes RRT RPFT, Pulmonary Function Laboratory, St Joseph Hospital, 172 Kinsley Street, Nashua, NH 03060. E-mail: jhaynes@sjhnh.org.
}

DOI: $10.4187 /$ respcare. 03312 related pain ${ }^{2-4}$; however, intradermal anesthetics are not widely used. ${ }^{2}$ The underutilization of intradermal anesthetics is explained by the unsubstantiated belief that the intradermal injection causes as much pain as the arterial puncture and that the volume of fluid infused into the dermal layer may make it more difficult to palpate the

See the Related Editorial on Page 141

radial artery..$^{2,3,5}$ In addition, respiratory therapists may not be permitted by their hospital or licensing board to administer intradermal anesthetics, adding an additional barrier to intradermal anesthetic use. RCTs of anesthetic creams have not shown efficacy over placebo in reducing pain related to arterial puncture..$^{6,7}$

Cryoanalgesia was first formally described by Hippocrates and was also used by ancient Egyptians, Persians, 
and Romans to alleviate pain. ${ }^{8}$ Since that time, cryoanalgesia has been widely used to reduce pain associated with numerous injuries, illnesses, and invasive procedures. ${ }^{8}$ For example, skin cooling before botulinum toxin injections and rhytidectomy (face lift) is associated with reduced procedure-related pain. ${ }^{9-11}$

If effective, cryoanalgesia would offer a noninvasive, non-pharmacologic, inexpensive, and readily available tool to reduce pain associated with arterial puncture. Moreover, cryoanalgesia could fill a void in settings that do not offer intradermal anesthesia before arterial puncture. This study sought to determine whether cryoanalgesia in the form of ice application could be an effective analgesic when applied before arterial puncture.

\section{Methods}

This was a prospective stratified RCT conducted in a hospital-based pulmonary function laboratory. This study was approved by the institutional review board of St Joseph Hospital. All study subjects gave written informed consent before study enrollment. This study is registered with ClinicalTrials.gov (NCT02065115).

\section{Subject Selection}

Subjects were recruited via a convenience sample. Eighty subjects $\geq 18$ y old referred to the pulmonary function laboratory with a physician order for an $\mathrm{ABG}$ test were sought to complete the study (Fig. 1). An equal number of experienced and naive arterial puncture subjects were sought for subgroup analysis. Recollection of a previous arterial puncture procedure (ie, more than documentation of a previous arterial puncture) was required to stratify a subject as experienced, whereas all others were stratified as naive (no recollection of previous arterial punctures). The primary outcome of the study was pain following arterial puncture as measured with a $100-\mathrm{mm}$ visual ana$\log$ scale (Fig. 2). Pretest power analysis indicated that 80 subjects would provide $80 \%$ power to detect a $40 \%$ difference in pain with a significance level of $.05 .^{3}$ The following exclusion criteria were applied: cold bluish hands and fingers; diagnosis of Raynaud's or scleroderma/CREST syndrome; history or signs of dementia, confusion, or cognitive impairment; blindness; not fluent in the English language; and non-palpable radial pulse in the wrist (necessitating brachial puncture).

\section{Study Protocol}

Subjects were randomized to the intervention or control group after being stratified for arterial puncture experience (see Fig. 1). The randomization schedule was generated a priori with a computerized randomization program. All

\section{QUICK LOOK}

\section{Current knowledge}

Arterial puncture is a common procedure in the hospital to allow assessment of pulmonary gas exchange. Compared with venipuncture, arterial puncture is more difficult, requires a deeper needle insertion, and is more painful for the patient. Methods for reducing the pain of arterial puncture have been described, but are not uniformly utilized or agreed upon.

\section{What this paper contributes to our knowledge}

Application of an ice bag to the proposed site of arterial puncture reduced the pain perceived by subjects. Using a visual analog scale of $0-100 \mathrm{~mm}$, subjects reported a measurable difference in pain perception, which may be of clinical importance.

subjects had their left and right wrists examined to determine which side had the strongest radial pulse (most suitable for puncture). All subjects underwent arterial puncture in the same laboratory setting and phlebotomy chair. Subjects in the intervention group had a small plastic bag filled with $12 \mathrm{oz}$ of crushed ice applied to the radial artery puncture site for $3 \mathrm{~min}$ (timed with stopwatch) without external compression or massage (Fig. 3). In preparation for this study, this approach was found to consistently lower radial artery puncture site skin temperature to $16-$ $18^{\circ} \mathrm{C}$ in an afebrile subject. Subjects were told that they were allowed to remove the ice before the 3-min period had concluded to relieve cold-related discomfort. Subjects were also permitted to briefly lift the ice bag off their wrists and then reapply. Subjects who requested early discontinuance of ice had their ABG drawn immediately. Subjects who could not tolerate ice application for a full 3 min remained in the study in accordance with intent-totreat analysis. ${ }^{12}$ The control group had their ABG drawn immediately after group assignment.

In both groups, a 1-mL ABG sample was drawn using a 23-guage needle (Portex Pro-Vent, Smiths Medical, Dublin, Ohio). All arterial punctures were performed according to laboratory policy. To eliminate technologist technique and skill as a variable, all samples were drawn by the principle investigator.

The number of successful first-attempt punctures was recorded. Any attempts requiring needle redirection were not classified as first-attempt success. Following arterial puncture, subjects were asked to rate the pain associated with the arterial puncture using a $100-\mathrm{mm}$ visual analog scale. One end of the $100-\mathrm{mm}$ visual analog scale represented no pain, whereas the other end represented worst pain (see Fig. 2). Subjects were asked to draw a perpen- 


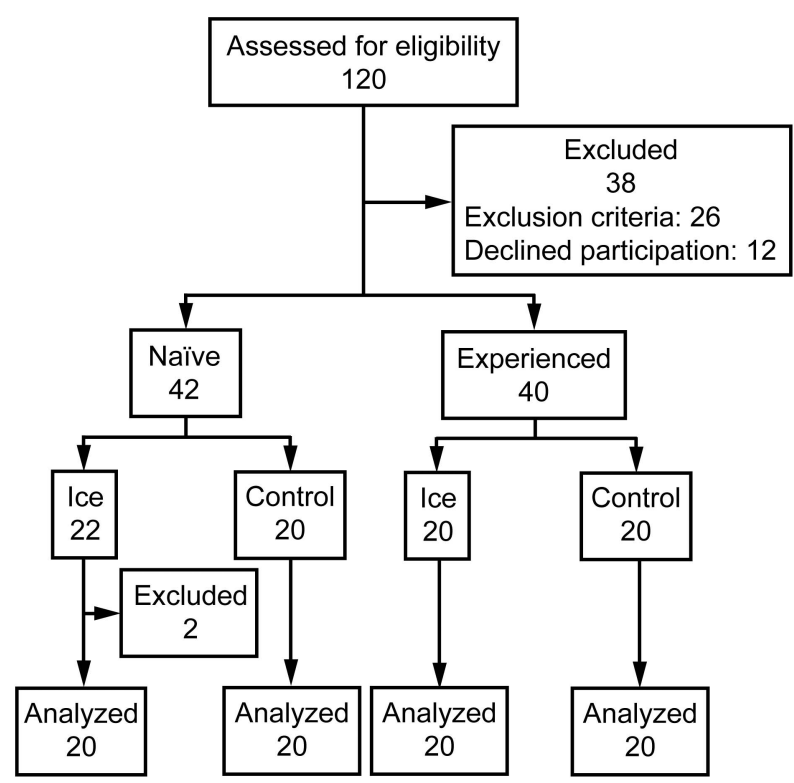

Fig. 1. Flow chart.

dicular line on the 100-mm scale to communicate their pain. To avoid any influence, all subjects were instructed to complete the visual analog scale after the principle investigator had left the laboratory with the ABG sample for analysis. The laboratory's administrative secretary collected the subject's visual analog scale and placed it in a sealed envelope before the investigator returned to the laboratory. After the study was closed to enrollment, an independent party (nurse researcher) was recruited to measure the pain scores from the visual analog scale.

\section{Statistical Analysis}

Group randomization and statistical computations were made using statistics software (Prism 4 and StatMate 2.0, GraphPad Software, La Jolla, California). Differences in continuous data were analyzed with the Student $t$ test for unpaired means and the Mann-Whitney test for unpaired medians. Differences in categorical data were analyzed with the Fisher exact test. Data are expressed as mean \pm SD or median and interquartile range (IQR). A 2-tailed $P$ value of $<.05$ was considered statistically significant.

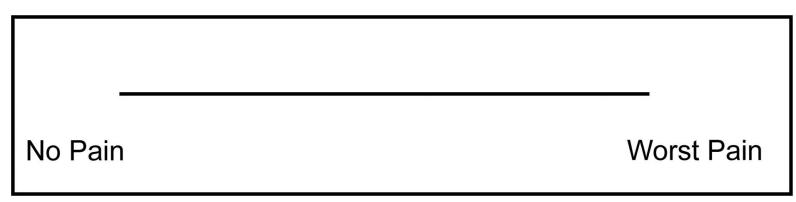

Fig. 2. Visual analog scale $(100 \mathrm{~mm})$ used to rate pain associated with arterial puncture. Subjects were asked to draw a perpendicular line to indicate their pain level.

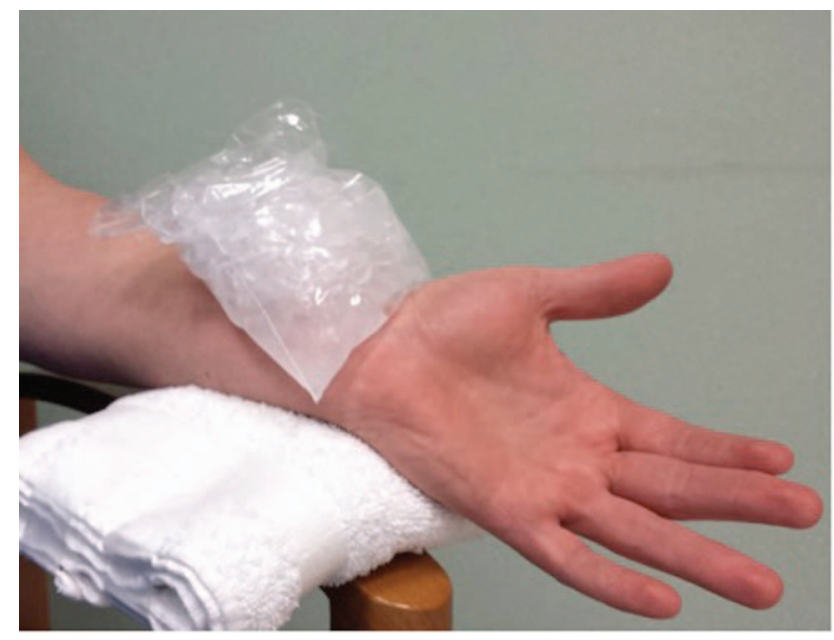

Fig. 3. A plastic bag containing 12 oz of crushed ice applied to the radial artery puncture site.

\section{Results}

For study enrollment, 120 potential candidates were screened (see Fig. 1): 12 declined study enrollment, and 26 met exclusion criteria. Eighty-two subjects entered the study. One subject was removed for violating the study protocol. One subject was removed because of a near-syncope episode during arterial puncture. Basic demographics were similar between both groups (Table 1).

Subjects pretreated with ice reported less pain from arterial puncture compared with subjects in the control group (mean visual analog scale $13.8 \pm 16.9$ vs $25 \pm 23 \mathrm{~mm}$, $P=.01$; median visual analog scale $7 \mathrm{~mm}$, IQR $1.5-19$ vs $20 \mathrm{~mm}$, IQR 4.5-38.5 mm, $P=.01$ ) (Fig. 4). Stratified analysis showed that visual analog scale pain scores were lower in the naive group when ice was applied (naive ice vs naive control: mean visual analog scale $11 \pm 14.3$ vs

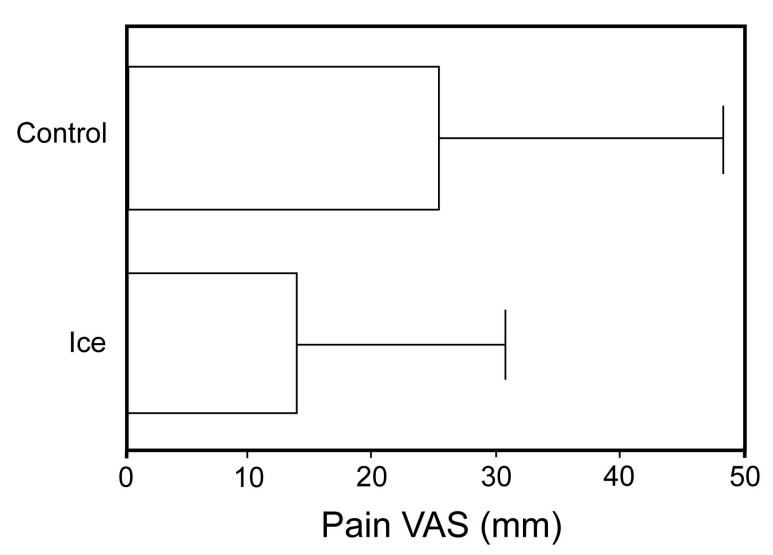

Fig. 4. Pain scores on the visual analog scale (VAS) following arterial puncture. Ice refers to subjects pretreated with cryoanalgesia (ice bag). Data are shown as mean $\pm \mathrm{SD}$. 
Table 1. Subject Demographics

\begin{tabular}{lccc}
\hline \hline & Intervention Group & Control Group & $P$ \\
\hline Age, y & $64.9 \pm 13.3$ & $64.4 \pm 15.3$ & .89 \\
Female, $\%$ & 47.5 & 55.5 & .65 \\
\hline
\end{tabular}

$26.5 \pm 25 \mathrm{~mm}, P=.02$; median visual analog scale $5 \mathrm{~mm}$, IQR $2-14.5$ vs $20 \mathrm{~mm}$, IQR $6.5-36 \mathrm{~mm}, P=.02$ ). Visual analog scale pain scores trended lower in the experienced group when ice was applied (experienced ice vs experienced control: mean visual analog scale $15.9 \pm 18.9$ vs $25.1 \pm 22 \mathrm{~mm}, P=.15$; median visual analog scale $8 \mathrm{~mm}$, IQR $0.5-26.5$ vs $23 \mathrm{~mm}$, IQR $3.5-40 \mathrm{~mm}, P=.08$ ). There was no difference in first-attempt success between groups (ice group: $85 \%$, control group: $82.5 \%, P>.99$ ). Only 3 subjects could not tolerate ice application for a full $3 \mathrm{~min}$ and requested early discontinuance.

\section{Discussion}

Arterial puncture for ABG analysis can be an uncomfortable procedure. This study found that the mean score on a 100-mm visual analog scale for arterial puncture without ice application was $25 \mathrm{~mm}$, very similar to that reported by Giner et $\mathrm{al}^{3}(28 \mathrm{~mm})$ and France et $\mathrm{al}^{4}(23.4 \mathrm{~mm})$ in subjects not receiving anesthetics or placebo. Although these mean scores do not indicate that arterial punctures usually cause severe pain, consideration should be given to the fact that the present study and that of Giner et $\mathrm{al}^{3}$ evaluated a single $\mathrm{ABG}$ procedure and were performed in out-patients with high first-attempt success. The reported pain associated with arterial puncture may be different when performed in hospitalized patients with anxious emotional states. Moreover, hospitalized patients may be subjected to repeated arterial punctures, sometimes by inexperienced personnel, and may have complicating factors such as hypotension and anasarca, potentially lowering first-attempt success. Indeed, a survey of subjects following discharge from an ICU found that arterial puncture for $\mathrm{ABG}$ analysis was the most frequently reported unpleasant experience. ${ }^{1}$

In this study, cryoanalgesia in the form of ice application for $3 \mathrm{~min}$ before arterial puncture significantly reduced procedure-related pain compared with a control procedure (ie, no ice). Cryoanalgesia reduced pain scores compared with the control in the naive subgroup, and there was a trend toward reduced pain in the experienced arterial puncture subgroup. Although the difference in pain between ice and control did not meet statistical significance in the experienced subgroup, this likely represents a type-2 error since this study was powered for the total group analysis. In addition, the 3-min ice application was well tolerated and did not affect first-attempt puncture success.
This study indicates that ice application may be an effective tool to reduce pain associated with arterial puncture. Moreover, cryoanalgesia with an ice bag is an attractive analgesic option since it is noninvasive, non-pharmacologic, inexpensive, and readily available. Although intradermal anesthetics are also effective in reducing arterial puncture pain, ${ }^{2-5}$ ice application appears to be an effective alternative for patients in settings in which anesthetics are not offered. However, cryoanalgesia may not be an acceptable technique for patients with Raynaud's or scleroderma/CREST syndrome. One potential hazard of this technique is tissue injury if ice is inadvertently applied for prolonged periods of time (eg, ice is applied, and the phlebotomist leaves the room and does not return in a timely manner).

Pain threshold and tolerance increase as skin temperature declines. ${ }^{13}$ Although not completely understood, the analgesic effect of ice application may be due to several mechanisms, including sensory nerve inactivation, reduced nerve conduction velocity, pain inhibition through inhibitory interneurons (pain gate), counterirritant effect, and release of endorphins. ${ }^{13,14}$ Achieving deep levels of cryoanalgesia can be time-consuming. Algafly and George ${ }^{13}$ found that the mean time to reduce ankle skin temperature to $10^{\circ} \mathrm{C}$ with ice packs was $26 \mathrm{~min}$. This level of cryoanalgesia would likely not be practical, well tolerated, or necessary for arterial puncture.

Clinicians should be aware that some forms of cryoanalgesia are more effective than others. For example, France et $\mathrm{al}^{4}$ showed that pain from arterial puncture was not affected by the use ethyl chloride coolant vapor. Moreover, crushed ice packs provide more effective cryoanalgesia than cold gel packs or cold water immersion. ${ }^{14-16}$ In addition, the quantity of ice used and the practice of compressing or massaging the ice against the body surface has a positive impact on skin and tissue cooling. ${ }^{14,17}$ For the purposes of this analysis, ice bags were applied with gravity alone, but based on my use of this technique in clinical settings, it does appear that massaging the ice bag against the radial artery puncture site results in more rapid cooling and presumably lower skin temperatures.

This study has a number of limitations. Although subjects reported less pain with cryoanalgesia, it is difficult to know if this finding represents a meaningful improvement in procedure-related morbidity. As mentioned above, this study was conducted exclusively in out-patients presenting for pulmonary function testing, and the pain associated with arterial puncture may be different when performed in hospitalized patients. In addition, this study used a single, non-blinded, experienced phlebotomist for arterial puncture, so the results may not be entirely reflective of pain scores and first-attempt arterial puncture success among a group of phlebotomists with varied experience and skill. This study used a standard ice exposure time $(3 \mathrm{~min})$ for 


\section{Cryoanalgesia to Reduce Pain From Arterial Puncture}

all subjects, whereas targeting a specific skin temperature might better tailor cryoanalgesia to individuals. Future studies should examine the use of ice bags to reduce arterial puncture in different patient populations using phlebotomists with varied experience and skill.

\section{Conclusions}

Cryoanalgesia in the form of ice application before arterial puncture is well tolerated, reduces procedure-related pain, and does not affect first-attempt puncture success.

\section{ACKNOWLEDGMENTS}

I thank Kathy Chilelli for assistance with data collection and Vickie Fieler PhD RN for assistance with data analysis.

\section{REFERENCES}

1. Turner JS, Briggs SJ, Springhorn HE, Potgieter PD. Patients' recollection of intensive care unit experience. Crit Care Med 1990;18(9): 966-968.

2. Lightowler JV, Elliott MW. Local anaesthetic infiltration prior to arterial puncture for blood gas analysis: a survey of current practice and a randomised double blind placebo controlled trial. J R Coll Physicians Lond 1997;31(6):645-646.

3. Giner J, Casan P, Belda J, Gaonzález M, Miralda RM, Sanchis J. Pain during arterial puncture. Chest 1996;110(6):1443-1445.

4. France JE, Beech FJ, Jakeman N, Benger JR. Anaesthesia for arterial puncture in the emergency department: a randomized trial of subcutaneous lidocaine, ethyl chloride or nothing. Eur J Emerg Med 2008; 15(4):218-220.

5. Hudson TL, Dukes SF, Reilly K. Use of local anesthesia for arterial punctures. Am J Crit Care 2006;15(6):595-599.
6. Aaron SD, Vandemheen KL, Naftel SA, Lewis MJ, Rodger MA. Topical tetracaine prior to arterial puncture: a randomized, placebocontrolled clinical trial. Respir Med 2003;97(11):1195-1199.

7. Tran NQ, Pretto JJ, Worsnop CJ. A randomized controlled trial of the effectiveness of topical amethocaine in reducing pain during arterial puncture. Chest 2002;122(4):1357-1360.

8. Trescot AM. Cryoanalgesia in interventional pain management. Pain Physician 2003;6(3):345-360.

9. Sarifakioglu N, Sarifakioglu E. Evaluating the effects of ice application on the pain felt during botulinum toxin type-a injections: a prospective, randomized, single-blind controlled trial. Ann Plast Surg 2004;53(6):543-546.

10. Saeliw P, Preechawai P, Aui-aree N. Evaluating the effects of ice application on patient comfort before and after botulinum type A injections. J Med Assoc Thai 2010;93(10):1200-1204.

11. Taghizadeh F, Ellison T, Traylor-Knowles M. Evaluation of pain associated with facial injections using CoolSkin in rhytidectomy. J Pain Res 2011:309-313.

12. Hollis S, Campbell F. What is meant by intention to treat analysis? Survey of published randomised controlled trials. BMJ 1999; 319(7211):670-674.

13. Algafly AA, George KP. The effect of cryotherapy on nerve conduction velocity, pain threshold, and pain tolerance. Br J Sports Med 2007;41(6):365-369; discussion 369.

14. Herrera E, Sandoval MC, Camargo DM, Salvini TF. Motor and sensory nerve conduction are affected differently by ice pack, ice massage, and cold water immersion. Phys Ther 2010;90(4):581-591.

15. Kanlayanaphotporn R, Janwantanakul P. Comparison of skin surface temperature during the application of various cryotherapy modalities. Arch Phys Med Rehabil 2005;86(7):1411-1415.

16. Chesterton LS, Foster NE, Ross L. Skin temperature response to cryotherapy. Arch Phys Med Rehabil 2002;83(4):543-549.

17. Janwantanakul $P$. The effect of quantity of ice and size of contact area on ice pack/skin interface temperature. Physiotherapy 2009;95(2):120-125.

This article is approved for Continuing Respiratory Care Education credit. For information and to obtain your CRCE

(free to AARC members) visit

www.rcjournal.com

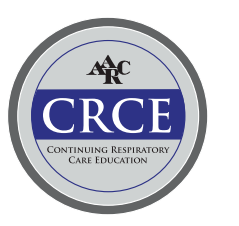

